Proceedings

\title{
Green Reduction of Silver Ions to Silver Nanoparticles Using Aqueous Plant Extracts ${ }^{\dagger}$
}

\author{
Ana-Alexandra Sorescu 1,2,* , Alexandrina Nuță ${ }^{1,3}$ and Ioana-Raluca Şuică-Bunghez ${ }^{1}$ \\ 1 The National Research \& Development Institute for Chemistry and Petrochemistry - ICECHIM, 202 \\ Splaiul Independentei, 6th district, 060021 Bucharest, Romania; alexnuta1256@yahoo.com (A.N.); \\ raluca_bunghez@yahoo.com (I.-R.Ş.-B.) \\ 2 Valahia University, 13th Sinaia Alley, 130004 Targoviste, Dambovita, Romania \\ * Correspondence: ana-alexandra.sorescu@icechim.ro; Tel.: +40-722-305-814 \\ + Presented at the 2nd International Online-Conference on Nanomaterials, 15-30 November 2020; Available \\ online: https://iocn2020.sciforum.net/.
}

Published: 15 Nobember 2020

\begin{abstract}
Silver nanoparticles are used in numerous scientific fields due to their versatile properties and because their surface can be functionalized with different biological molecules. Their synthesis follows both conventional and unconventional routes and, in recent years, the methods that start from plants are constantly detaching from the hazardous, time consuming chemical methods. This paper presents the green synthesis of silver nanoparticles from St. Benedict's herb (Geum urbanum) and its corresponding aqueous extracts via two different temperature conditions: room temperature, for $24 \mathrm{~h}$ with no additional stirring and $50^{\circ} \mathrm{C}$, for $30 \mathrm{~min}$ under a constant stirring of $600 \mathrm{rpm}$. Silver nanoparticles were then characterized using UV-Vis spectroscopy at wellestablished time intervals in the range of $250-650 \mathrm{~nm}$ and FTIR spectra were recorded to show the presence of different functional groups. DLS technique was used to investigate the particle size and zeta potential was also measured to analyze the stability of the green synthesized silver nanoparticles. TEM microscopy revealed a spherical-shape profile of the green synthesized silver nanoparticles and optical microscopy images were also recorded. Also, the antioxidant activity was determined using the DPPH method and compared to that of the crude aqueous extracts.
\end{abstract}

Keywords: green synthesis; silver nanoparticles; Geum urbanum; antioxidant activity

\section{Introduction}

Metallic nanoparticles are at the leading edge of nanotechnology, a scientific field that in constantly and rapidly growing ever since the physicist Richard P. Feynman, a Nobel Prize laureate, first visualized it in 1959. Practically, metallic nanoparticles can be considered a bridge between bulk materials and molecular structures and, therefore, they exhibit unique physical-chemical properties that allows their use in numerous applications [1,2].

St. Benedict's herb (Geum urbanum) is an astringent herb, used mainly for the treatment of different problems affecting the mouth, throat and the gastro-intestinal tract. It helps heal mouth ulcers and reduces irritation of the stomach and gut.

The phytochemicals that naturally occur in Geum urbanum such as saponins, flavonoids, carbohydrates or polyphenols have anti-inflammatory and antioxidant properties and can reduce the metal ions to metallic nanoparticles in a one - pot environmentally friendly synthesis $[3,4]$.

Silver nanoparticles (AgNPs) due to their antibacterial, antioxidant and antifungal properties, have various applications in medicine, different industry branches, biology, as sensors, drug delivery systems, etc. [5,6]. 
This paper presents the green synthesis of silver nanoparticles from St. Benedict's herb (Geum urbanum) and its corresponding aqueous extract via two different temperature conditions: room temperature and $50{ }^{\circ} \mathrm{C}$. Silver nanoparticles are then characterized using UV-Vis and FTIR spectroscopy and their antioxidant activity is determined using the DPPH method. TEM microscopy revealed a spherical-shape profile of the green synthesized silver nanoparticles and optical microscopy images were also recorded.

\section{Materials and Methods}

\subsection{Materials}

Silver nitrate $\left(\mathrm{AgNO}_{3}\right)$, $\mathrm{DPPH}$, (2,2-diphenyl-1-picryl-hydrazyl-hydrate stable free radical). The distilled water used in all our experiments was freshly prepared in the laboratory.

Geum urbanum was purchased from the local natural shop as dried plant (tea).

\subsection{Preparation of Aqueous Plant Extracts}

St. Benedict's herb (Geum urbanum) was purchased ready dried and used as such for the preparation of the aqueous extract as follows: $25 \mathrm{~g}$ of dried plant were weighted, transferred into a "French press" type extractor and $250 \mathrm{~mL}$ distilled water was added; the mixture was left for $24 \mathrm{~h}$, at $4{ }^{\circ} \mathrm{C}$ (in a refrigerator) to infuse so that all the active ingredients were released into the aqueous extract; the resulted aqueous extract was filtered and a clear aqueous extract was obtained.

\subsection{Green Synthesis of Silver Nanoparticles}

An aqueous $1 \times 10^{-3} \mathrm{M}$ solution of silver nitrate $\left(\mathrm{AgNO}_{3}\right)$ was freshly prepared and used for the phytosynthesis of AgNPs from Geum urbanum as follows: $5 \mathrm{~mL}$ aqueous extract was mixed with 50 $\mathrm{mL} 1 \times 10^{-3} \mathrm{M} \mathrm{AgNO}_{3}$ solution and left for $24 \mathrm{~h}$ in the dark, at room temperature. After $24 \mathrm{~h}$, the Geum urbanum-AgNPs (GU-AgNPs) was agitated in an ultrasound bath, for $30 \mathrm{~min}$, at $50 \mathrm{rpm}$. At 500 $\mathrm{C}, 5 \mathrm{~mL}$ aqueous extract was mixed with $50 \mathrm{~mL} 1 \times 10^{-3} \mathrm{M} \mathrm{AgNO}_{3}$ solution, heated under continuous stirring $(500 \mathrm{rpm})$ for $30 \mathrm{~min}$. The heat was turned off and the GU-AgNPs suspension was stirred at room temperature for $30 \mathrm{~min}$ and left for $24 \mathrm{~h}$ in the dark.

\subsection{Characterization Methods}

The absorption spectra for Geum urbanum aqueous extract and AgNPs were recorded using a M 400 Carl Zeiss Jena UV-Vis spectrometer in the wavelength range of 250-800 nm. Fourier transform infrared spectroscopy (FTIR) spectra were recorded using a Vertex 80 FT-IR spectrometer equipped with high-resolution Hyperion 3000 microscope, in the range of $8000-400 \mathrm{~cm}^{-1}$.

Dynamic light scattering (DLS) spectra were recorded using a Zetasizer Nano SZ-Malvern instrument with a computer connected and preinstalled Zetasizer software that controls the measurements. Antioxidant activity for Geum urbanum aqueous extract and AgNPs was measured using a standard method: a DPPH solution was prepared in ethanol and $0.5 \mathrm{~mL}$ aqueous extract was mixed with $1 \mathrm{~mL} 0.02 \mathrm{mg} / \mathrm{mL}$ DPPH solution.

The solutions were tested by recording and noting the absorbance at $517 \mathrm{~nm}$. A blank probe was prepared in parallel by mixing $0.5 \mathrm{~mL}$ distilled water with $1 \mathrm{~mL} 0.02 \mathrm{mg} / \mathrm{mL}$ DPPH solution and the spectrum was recorded at the same wavelength $[7,8]$.

The antioxidant activity (AA\%) was calculated using the formula:

$$
\mathrm{AA} \%=[(\text { Acontrol }- \text { Asample }) / \text { Acontrol }] \times 100,
$$

where:

- Acontrol is the absorbance of the blank DPPH solution and

- Asample represents the absorbance Geum urbanum aqueous extracts mixed with $0.02 \mathrm{mg} / \mathrm{mL}$ DPPH solution. 


\section{Results and Discussions}

\subsection{Ultraviolet-Visible (UV-Vis) Results}

An absorption at a wavelength around $270 \mathrm{~nm}$ and $370 \mathrm{~nm}$ is characteristic for phenolic acids and/or their derivatives (flavones or quinones) [9]. In the case of the aqueous extract from Geum urbanum, the phenolic acids and flavonoids were identified at 273 and $374 \mathrm{~nm}$ respectively. The bioreduction of silver ions was first visually observed by a change of color of the colloidal solutions from light green to yellow-greenish whatever the temperature conditions used for the green synthesis of AgNPs and then it was confirmed by the UV-Vis recordings (Table 1). For AgNPs, the specific absorbance is situated between $430 \mathrm{~nm}-450 \mathrm{~nm}$.

Table 1. UV - Vis absorptions for the green synthesized AgNPs.

\begin{tabular}{ccc}
\hline Aqueous Extract & AgNPs Room Temperature & AgNPs 50 ${ }^{\circ} \mathbf{C}$ \\
\hline St. Benedict's herb (Geum urbanum) & $445 \mathrm{~nm}$ & $448 \mathrm{~nm}$ \\
\hline
\end{tabular}

\subsection{Fourier Transform Infrared Spectroscopy (FTIR) Results}

FTIR spectra allows the identification of different functional groups at different wavelengths. All the FTIR spectra were recorded using dried samples. The strong band observed around $3300 \mathrm{~cm}^{-1}$ for the aqueous extract of St. Benedict's herb (Geum urbanum) and its AgNPs shows the presence of alkynes while in the region of $1600 \mathrm{~cm}^{-1} \mathrm{C}=\mathrm{O}$ bonds were present. The medium absorption bands recorded in the range of $2800-3000 \mathrm{~cm}^{-1}$ are characteristic for alkyl-methyl bonds and the clear band around $1460 \mathrm{~cm}^{-1}$ in Geum urbanum aqueous extract is characteristic for the imidazole ring. The absorptions between $1300-1500 \mathrm{~cm}^{-1}$ regions are a results of base sugar vibrations.

A very important result is the peak at $1200 \mathrm{~cm}^{-1}$ present only in the aqueous extract of Geum urbanum, correspondent to amides, proteins and enzymes and absent in the FTIR spectra of GUAgNPs, thus explaining the $\mathrm{Ag}^{+}$reduction.

\subsection{Antioxidant Activity Results}

Antioxidant activity was evaluated using the DPPH method and the results are presented in Table 2. It is clear that, for GU-AgNPs, AA (\%) has higher values that the one specific to the aqueous extract, with a slight increase in the case of GU-AgNPs green synthesized at room temperature. AA (\%) for the Geum urbanum aqueous extract was calculated at $56.77 \%$.

Table 2. Antioxidant activity for the green synthesized AgNPs.

\begin{tabular}{ccc}
\hline Crt. no. & AA (\%) Room Temperature & AA (\%) $\mathbf{5 0}{ }^{\circ} \mathbf{C}$ \\
\hline Antioxidant activity & 92.56 & 90.26 \\
\hline
\end{tabular}

\subsection{Dynamic Light Scaterring (DLS) Results}

Dynamic light scattering (DLS) recordings (Figure 1) were used to determine the size distribution profile of the GU-AgNPs in suspension and the Zeta potential was allows a proper analyze of the stability of the colloidal suspensions (Table 3). 


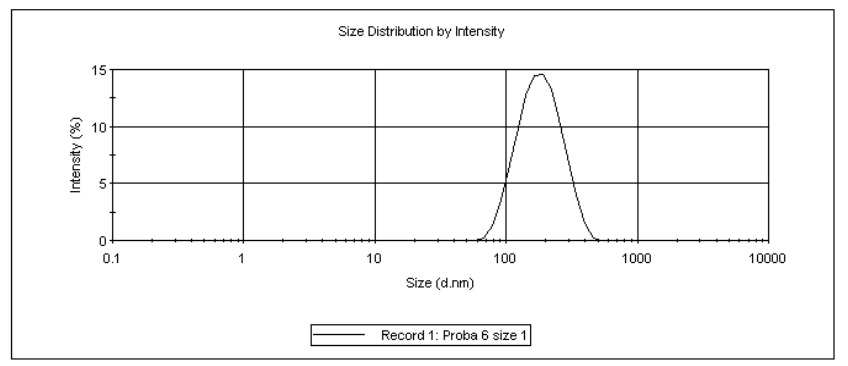

Figure 1. DLS spectrum for the RA-AgNPs at $50{ }^{\circ} \mathrm{C}$.

Table 3. DLS measurements and zeta potential.

\begin{tabular}{ccccc}
\hline Sample & Dm $($ d.nm) & P1...i $(\mathbf{d} . \mathbf{n m})$ & PdI & PZ $(\mathbf{m V})$ \\
\hline GU-AgNPs room temperature & 178 & $P_{1}=180$ & 0.178 & -17 \\
\hline GU-AgNPs $50^{\circ} \mathrm{C}$ & 185 & $P_{1}=176$ & 0.168 & -15 \\
\hline
\end{tabular}

\section{Conclusions}

This original research presents the green synthesis of silver and gold nanoparticles from aqueous extracts of St. Benedict's herb (Geum urbanum), a medicinal plant recognized for its numerous health benefits. The aqueous extract of St. Benedict's herb (Geum urbanum) was prepared after a $24 \mathrm{~h}$ cold infusion at $4{ }^{\circ} \mathrm{C}$, using commercially available tea. Silver nanoparticles (AgNPs) were prepared at room temperature, in the dark, for $24 \mathrm{~h}$ and at $50^{\circ} \mathrm{C}$, under continuous stirring at $500 \mathrm{rpm}$, for $30 \mathrm{~min}$. The formation of GU-AgNPs was at first visually observed by the change of the color of the colloidal solutions and then confirmed by UV-Vis recordings. The characteristic absorption for GU-AgNPs was observed at $427 \mathrm{~nm}$. The antioxidant activity showed a considerable increase for AgNPs as compared to plain Geum urbanum aqueous extract and Dynamic light scattering (DLS) measurements prove the presence of GU-AgNPs in the tested samples. Also, the bioactive compounds found in Geum urbanum act as reducing and capping agents, preventing the agglomeration of the particles and stabilizing the nanoparticles.

Author Contributions: Conceptualization, A.A.S. and A.N.; methodology, A.A.S. and A.N.; physical-chemical investigations, A.A.S., A.N. and I.R.S.B.; writing-original draft preparation, A.A.S.; writing-review and editing, A.A.S. and A.N.; visualization, I.R.S.B.; supervision, A.N. All authors have read and agreed to the published version of the manuscript.

Conflicts of Interest: The authors declare no conflict of interest.

\section{References}

1. Kumar, V.; Yadav, S.K. Plant-mediated synthesis of silver and gold nanoparticles and their applications. J Chem. Tech. Biotech. 2009, 84, 151-157.

2. Khan, I.; Saeed, K. Nanoparticles: Properties, applications and toxicities. Arabian J. Chem. 2017, 5, $255-260$.

3. Rauwel, P.; Küünal, S.; Ferdov, S.; Rauwel, E. A review on the green synthesis of silver nanoparticles and their morphologies studied via TEM. Adv. Mater. Sci. Eng. 2015, 8, 50-59.

4. Biswas, T.K.; Sarkar, S.M.; Yusoff, M.M.; Rahman, M.L. Synthesis and characterization of azobenzenebased gold nanoparticles for photo-switching properties. J. Mol. Liq. 2016, 214, 231-237.

5. Jeong, J.H.; Lee, J.W.; Kim, K.S.; Kim, J.-S.; Han, S.N.; Yu, C.Y.; Lee, J.K.; Kwon, Y.S.; Kim, M.J. Antioxidant and antimicrobial activities of extracts from a medicinal plant, Sea buckthorn. J. Korean Soc. Appl. Biol. Chem. 2010, 53, 33-38.

6. Biju, J.; Sulaiman, C.T.; Satheesh, G.; Reddy, V.R.K. Total phenolics and flavonoids in selected medicinal plants from Kerala. Int. J. Pharm. Pharmacol. Sci. 2014, 6, 406-408. 
7. Alam, N., Hossain, M.; Khalil, M.I.; Moniruzzaman, M.; Sulaiman, S.A.; Gan, S.H. High catechin concentrations detected in Withania somnifera (Ashwagandha) by high performance liquid chromatography analysis. BMC Complement. Altern. Med. 2011, 11, 208-211.

8. Frackowiak, D.; Waszkowiak, A.; Manikowski, H.; Ion, R.M. The interactions of phthalocyanines with stimulated and resting human peripheral blood mononuclear cells. Acta Biochim. Polon. 2001, 48, 257-263.

9. Bezuneh, T.; Kebede, E.M. UV-Visible spectrophotometric quantification of total polyphenol in selected fruits. Int. J. Nut. Food Sci. 2015, 4, 397-40.

Publisher's Note: MDPI stays neutral with regard to jurisdictional claims in published maps and institutional affiliations.

(C) 2020 by the authors. Submitted for possible open access publication under the terms and conditions of the Creative Commons Attribution (CC BY) license (http://creativecommons.org/licenses/by/4.0/). 